\title{
FUERZAS DE SUPERFICIE Y ADHESIÓN EN SISTEMAS CELULÓSICOS: NUEVA FORMA DE EVALUAR FIJACIÓN/DISPERSIÓN DE RESINA EN LA FABRICACIÓN DE PAPEL/CELULOSA
}

\author{
SURFACE FORCES AND ADHESION IN CELLULOSE SYSTEMS: NEW WAY TO \\ EVALUATE RESIN FIXATION/DISPERSION IN THE MANUFACTURE OF PAPER/ \\ CELLULOSE
}

Sergio M. Acuña ${ }^{1}$, Pedro G. Toledo ${ }^{2}$

\begin{abstract}
RESUMEN
Las fuerzas superficiales entre partículas coloidales de resina y fibra dominan el comportamiento y las propiedades finales de papel y celulosa. Aquí se describe el uso de Microscopía de Fuerza Atómica (AFM) para medir directamente las fuerzas de interacción entre la superficie de un substrato plano 'funcionalizado' con resina de madera y la superficie de una microesfera de vidrio en soluciones de electrolito a $\mathrm{pH}$ controlado y a temperatura ambiente. El substrato convertido en hidrofílico es una hoja de poliestireno recubierta con una película ultra fina de resina natural. La carga superficial del substrato 'funcionalizado' imita la de las micelas de resina, la microestructura preferida de la resina en agua, y la carga sobre la microesfera imita la de las fibras de madera. Las curvas de fuerza AFM son interpretadas a la luz del balance entre fuerzas atractivas -van der Waals- y repulsivas -electrostáticas- de la teoría continua clásica DLVO de fuerzas para sistemas coloidales. Las medidas muestran una fuerte y persistente repulsión de muy corto rango, a distancias de separación menores a $100 \AA$, que no puede ser explicada por la teoría DLVO. Estas fuerzas repulsivas que actúan como barreras al contacto o a la coagulación tienen su origen en capas de agua altamente ordenadas en la vecindad de las superficies eléctricamente cargadas. El tamaño e intensidad de la barrera dependen de la magnitud y densidad de la carga eléctrica en las superficies que interactúan, que a su vez dependen de sus composiciones químicas y del medio acuoso. La repulsión aumenta con el $\mathrm{pH}$ y disminuye con la concentración y tamaño del electrolito. Fuerzas AFM de alejamiento entre substrato y microesfera, después de ocurrido el contacto, revelan una correlación aparentemente no reportada antes entre concentración de electrolito y adhesión. La adhesión aumenta con la concentración y tamaño del electrolito. Fenómenos complejos como dusting, desprendimiento de resina durante el uso del papel, pueden ser controlados mediante regulación del ambiente fluido durante el proceso de fabricación.

Palabras clave: AFM, nanofuerzas, resina, pitch, fijación, adhesión, fabricación de papel
\end{abstract}

\section{ABSTRACT}

Surface and adhesive forces between colloidal wood particles of resin and fiber dominate the behavior and final properties of paper and cellulose. This paper describes the use of Atomic Force Microscopy (AFM) to measure the interaction force between a resin 'functionalized' substrate and a glass microsphere in aqueous $\mathrm{pH}$-controlled electrolyte solutions at ambient temperature. The waterwet made substrate is a hydrophobic polystyrene film coated with an extremely thin film of wood fatty and resin acids. The surface charge on the 'functionalized' substrate mimics that on resin micelles, the preferred microstructure of resin in water, and the charge on the microsphere mimics that on wood fibers. AFM force curves are analyzed to the light of the balance between attractive forces -van derWaals- and repulsive forces -electrostatic- from the classical continuum DLVO theory of colloidal forces. Force measurements show strong and persistent short-range repulsive forces at distances less than $100 \AA$ which are not explained by the DLVO theory. These repulsive forces that act as barriers to contact or coagulation originate on highly ordered water in the neighborhood of the charged surfaces.

${ }^{1}$ Departamento de Ingeniería en Alimentos, Universidad del Bío-Bío, Chillán, Chile

${ }^{2}$ Departamento de Ingeniería Química y Laboratorio de Superficies (ASIF). Universidad de Concepción, Concepción, Chile

Autor para correspondencia: sacuna@ubiobio.cl

Recibido: 13.05.2010 Aceptado: 12.10 .2010 
The barrier size and intensity depend on the magnitude and density of the electrical charges on the interacting surfaces, which in turn depends on their chemical composition, and on the aqueous media. Repulsion increases with $\mathrm{pH}$ and decreases with electrolyte concentration. AFM flat-microsphere pull-off forces reveal an apparently unreported correlation between electrolyte concentration and adhesion. Adhesion increases with electrolyte concentration and size. Complex phenomena such as dusting, the release of resin upon paper use due to poor resin-fiber bondage, can thus be controlled by regulating the aqueous media during papermaking.

Keywords: AFM, nanoforces, resin, pitch, bondage, adhesion, papermaking

\section{INTRODUCCIÓN}

El manejo y control de la resina de madera en la fabricación de celulosa y papel ofrece un gran desafío que a la fecha no ha sido abordado completamente. La resina es de carácter lipofílico y se encuentra constituida generalmente por ácidos resínicos, ácidos grasos, esteroles, triglicéridos y ésteres de esterol (Fengel y Wegener 1989). La cantidad y composición de resina dependen de factores como especie de planta, edad y lugar de crecimiento (Gutiérrez y del Río 2003; Freire et al. 2005). La resina mal controlada conduce a una serie de problemas graves operacionales y de calidad de producto. Por ejemplo, en la fabricación de papel la resina genera depósitos pegajosos en la máquina papelera, donde la resina toma el nombre de 'pitch'; en la fabricación de celulosa la resina es responsable de manchas obscuras que bajan la categoría del producto (Gutiérrez et al. 1998; Silvestre et al. 1999; Gutiérrez y del Río 2005). Claramente, se requiere un salto cualitativo en la comprensión del comportamiento de la resina en solución acuosa y de su interacción con las fibras de madera y en sus dependencias con factores como $\mathrm{pH}$, fortaleza iónica, tipo y dosis de aditivos y temperatura.

Durante las últimas décadas, varios instrumentos han sido desarrollados principalmente para medir interacciones entre superficies sólidas macroscópicas y entre una superficie macroscópica plana y una partícula de tamaño coloidal. El Microscopio de Fuerza Atómica (Atomic Force Microscopy, AFM) (Binning et al. 1986) y el equipo de fuerza superficial (Surface Force Apparatus, SFA) (Israelachvili y Adams 1976) son los más usados, pero el AFM es el favorito debido a la simplicidad de su manejo, la posibilidad de usar una gran gama de substratos y la opción de trabajar en distintos ambientes fluidos. AFM surgió como una modificación de la Microscopía de Efecto Túnel (STM, Scanning Tunneling Microscopy) reemplazando la corriente inducida entre el extremo de una sonda conductora y la superficie de interés por la interacción física entre ambas (Binning et al. 1982; Binning et al. 1986). Esta interacción se debe a fuerzas atractivas o repulsivas entre átomos (o moléculas) que conforman las dos superficies que interactúan. Típicamente una de las superficies, la del substrato de interés, es macroscópica y la otra es la punta atómicamente aguda de una pirámide, o la de una microesfera, adherida al extremo de una barra o cantilever. Al cantilever con la pirámide o la esfera nos referimos como cantilever modificado. AFM permite una gran variedad de análisis, siendo los más utilizados la topografía a escala de $\mathrm{nm}$, donde se utiliza el cantilever modificado con la pirámide de punta atómica y el estudio de fuerzas a distancias moleculares, donde se utiliza el cantilever modificado con la microesfera (Acuña 2007). Aplicaciones de AFM abundan en la literatura, tanto para determinar nanoestructuras como para determinar interacciones. Por ejemplo, interacciones entre materiales biológicos, como ADN (Lee et al. 1994) y otras proteínas (Koheler et al. 2000; Chen et al. 1997), entre monocapas y dobles capas lipídicas (Richter et al. 2006, Schönherr et al. 2004, Dufrêne et al. 1997), entre bacterias y mica y entre levaduras y superficies recubiertas (Bowen et al. 2000, 2001; Ong et al. 1999), entre películas de celulosa (Rundlöf et al. 2000; Zauscher y Klingenberg, 2000), y entre monocapas de lignina depositada en medio acuoso (Micic et al. 2001).

En este trabajo se describe el uso de AFM para medir directamente y por primera vez, las fuerzas de interacción entre la superficie hidrofílica de una película ultradelgada de resina de madera depositada sobre un substrato plano y una microesfera de vidrio cuya carga superficial imita la de una fibra de madera en ambiente fluido controlado. Las fuerzas medidas se racionalizan mediante teoría continua de fuerzas intersuperficiales. Estas fuerzas son las que deben sintonizarse adecuadamente 
para maximizar la fijación y estabilidad de la resina a la fibra en la fabricación de papel y para minimizar tal fijación en la fabricación de celulosa. En el presente trabajo se centra la discusión sobre el efecto de la concentración y tamaño de electrolitos, soluciones acuosas de $\mathrm{NaCl}, \mathrm{CaCl}_{2} \mathrm{y} \mathrm{AlCl}_{3}, \mathrm{y}$ $\mathrm{pH}$.

\section{MATERIAL Y MÉTODO}

Preparación de cantilevers modificados. Un cantilever modificado es una barra de nitruro de silicio $\left(\mathrm{Si}_{3} \mathrm{~N}_{4}\right)$, con longitudes típicas de 100 y $200 \mu \mathrm{m}$, en cuyo extremo se adhiere una microesfera. El procedimiento de modificación utilizado aquí es el mismo que se encuentra descrito en Acuña y Toledo (2008). La calidad de los cantilevers modificados se verificó mediante microscopía electrónica de barrido en un equipo SEM [ETEC, Modelo AUTOSCAN, USA]. Esta técnica es destructiva por lo que los análisis SEM se limitaron a unos pocos cantilevers.

Calibración de cantilevers modificados. Los cantilevers poseen una constante elástica definida, cuyo valor es proporcionado por el fabricante. Una vez que el cantilever ha sido modificado con la microesfera, la constante elástica cambia y debe ser calculada o medida nuevamente. En este estudio, la constante elástica se midió nuevamente y para ello se utilizó un método basado en estándares de calibración. Una ventaja de esta metodología es que la medición se realiza del mismo modo que la de fuerzas, sólo que en este caso la medición se realiza sobre el extremo del cantilever de calibración cuya constante elástica se conoce.

Preparación de substratos "funcionalizados" con resina. El objetivo aquí fue recubrir un substrato plano, originalmente hidrofóbico, con una película delgada de resina de madera, de modo que las anfifilas de resina quedaran orientadas con sus colas alifáticas hacia la superficie del substrato y las cabezas polares hacia el aire atmosférico. Así, el resultado es un substrato recubierto con carácter hidrofílico. La resina de madera utilizada fue tomada directamente desde un corte en un pino radiata en pie. Esta resina fue filtrada en los laboratorios de Norske-Skog y refiltrada en nuestro Laboratorio de Superficies ASIF. La Figura 1a muestra un dibujo esquemático de un substrato recubierto. Esta es exactamente la orientación que adopta la resina en el proceso de fabricación de papel, excepto que en ese caso la configuración es micelar, la geometría esférica y el tamaño coloidal. Para la preparación de los substratos recubiertos se utilizó el siguiente procedimiento. Se preparó una suspensión coloidal de resina y se elevó su temperatura a $95^{\circ} \mathrm{C}$ para solubilizar la mayor cantidad de resina, luego se dejó enfriar. Cuando su temperatura alcanzó $90^{\circ} \mathrm{C}$, se sumergió el substrato de interés y se retiró después de 5 segundos; luego se dejó secar a temperatura ambiente. Como substratos se utilizaron muestras de $3 \times 1 \mathrm{~cm}^{2}$ de transparencias para impresoras láser [Avery Dennison Corporation, USA]. El experimento se repitió a $80,70,60$ y $50^{\circ} \mathrm{C}$ a fin de obtener máximo recubrimiento y correcta orientación de las colas alifáticas de las anfifilas de resina respecto a la superficie del substrato. Temperaturas altas aseguraron mayor disponibilidad de resina en suspensión, lo que favoreció mayor recubrimiento, pero también mayor movilidad de las anfifilas de resina, lo que atentó contra la orientación. El mejor balance se determinó a partir de medidas de ángulos de contacto de gotas de agua bidestilada depositadas sobre la superficie de los substratos recubiertos de resina. La temperatura óptima de recubrimiento resultó ser $60^{\circ} \mathrm{C}$; a esta temperatura el ángulo de contacto, medido a través del agua, resultó ser el más bajo revelando un mayor carácter hidrofílico del substrato recubierto. Se prepararon muestras suficientes para verificar la reproducibilidad de los ángulos de contacto medidos, para análisis topográfico, y para medidas de fuerzas de interacción de superficie y adhesión. Como alternativa también se prepararon substratos planos de vidrio [B\&C, Alemania] hidrofobizados con hexametildisilazano [Merk, USA] según el método de Díaz (2005) y luego cubiertos con una película delgada de una mezcla de ácidos resínicos y grasos de madera, el proceso de recubrimiento es similar al descrito para los substratos originalmente hidrofóbicos.

Angulos de contacto. Para la determinación de ángulos de contacto de substratos con y sin recubrimiento de resina se utilizó un goniómetro [Ramé-Hart 100-07-00, USA]. 
Análisis topográfico. Para el análisis topográfico de las superficies de substratos con y sin recubrimiento de resina y de microesferas de vidrio se utilizó el AFM Dimension 3100-240, con un barrido horizontal máximo de $100 \times 100 \mu \mathrm{m}^{2}$ y un desplazamiento vertical máximo de $\sim 7 \mu \mathrm{m}$. Las condiciones de operación fueron atmosféricas. Se realizaron barridos a distintas resoluciones a fin de determinar características topográficas superficiales en diversas escalas. Se utilizó un cantilever modificado con punta piramidal de nitruro de silicio con una constante de fuerza de $0.12 \mathrm{~N} / \mathrm{m}$. El instrumento se utilizó en modo contacto, que permite óptima resolución de imagen; la punta del cantilever es simplemente arrastrada sobre la superficie y la imagen que resulta es un mapa topográfico de la superficie de la muestra. Se utilizó un software de análisis de imágenes para el procesamiento de las imágenes de AFM [Nanoscope IIIa DI v4.42, Veeco, USA].
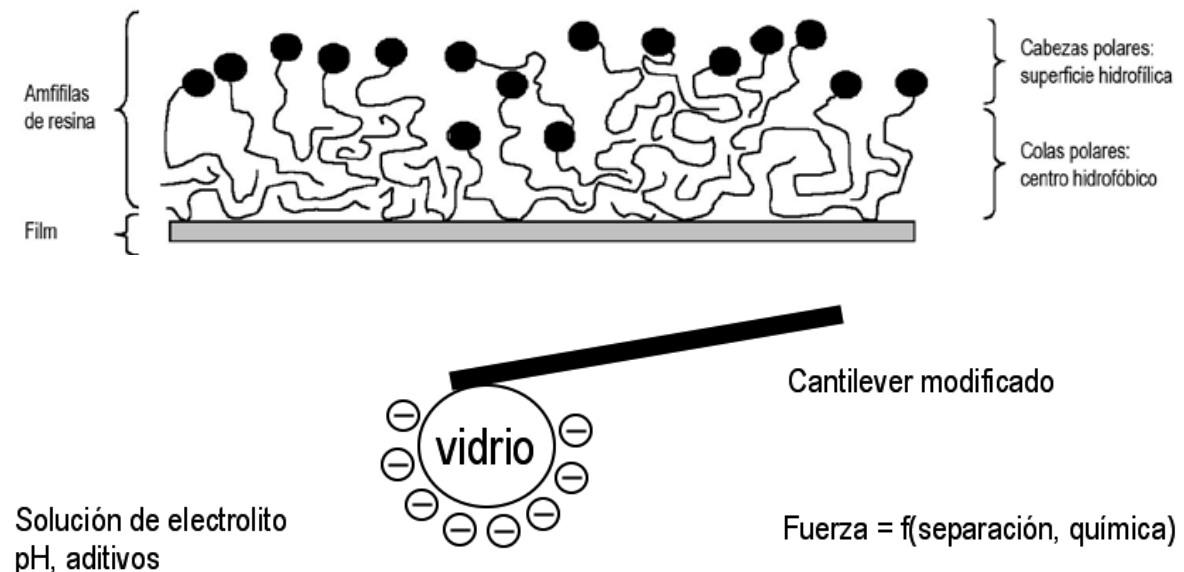
$\mathrm{pH}$, aditivos
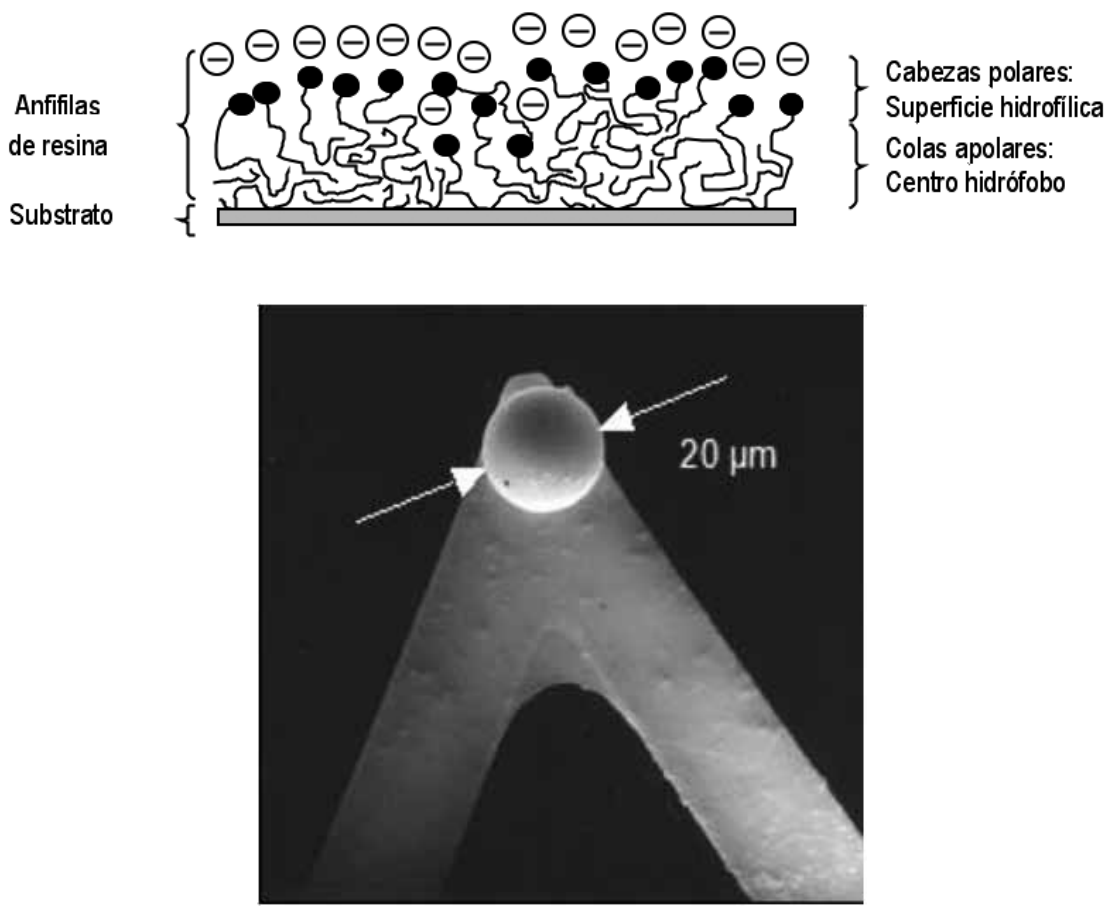

Figura 1. Dibujo esquemático de substrato hidrofóbico plano recubierto con una película ultradelgada de anfifilas de resina de madera (a). Dibujo esquemático de la medición de fuerzas de interacción entre resina de madera sobre un substrato plano y una microesfera de vidrio cuya carga superficial emula la de una fibra (b). Imagen SEM de cantilever modificado con microesfera de vidrio de $20 \mathrm{~mm}$ de diámetro (c). 
Obtención e interpretación de curvas de fuerza. Para la medición de fuerzas de superficie y adhesión entre un substrato plano recubierto de resina y una microesfera de vidrio montada en el extremo de un cantilever se usó un microscopio de fuerza atómica AFM [AFM-3 Multimode, Veeco, USA] equipado con una estación de control [Nanoscope IIIa SPM, Veeco, USA], una celda de fluidos [Veeco, USA], un cojinete de silicona para aislar vibraciones [Veeco, USA] y una cubierta acústica [Veeco, USA]. Las muestras fueron manejadas con pinzas para evitar contaminación. Una vez montado el substrato y el cantilever con la microesfera en la celda de fluido se procedió a inundarla con solución de electrolito. Después de dejar que el sistema alcanzara equilibrio se procedió a acercar el cantilever a la superficie del substrato y a medir la deflexión del cantilever en función de la distancia de separación, debido a las fuerzas atractivas o repulsivas que se manifiesten según las condiciones del ambiente fluido. La obtención de curvas de fuerza intersuperficiales, acercamiento substrato-microesfera y adhesión, alejamiento substrato-microesfera, se realizó a partir de datos experimentales de Deflexión vs. Posición $Z$ del cantilever entregados por el software del instrumento [Nanoscope IIIa DI v4.42, Veeco, USA]. La Figura $1 \mathrm{~b}$ muestra un dibujo esquemático de la medición de fuerzas de interacción entre resina de madera sobre un substrato plano y una microesfera de vidrio cuya carga superficial imita la de una fibra.

Preparación de soluciones acuosas. Se prepararon soluciones de $\mathrm{NaCl}, \mathrm{CaCl}_{2}$ y $\mathrm{AlCl}_{3}$ [Merck, Chile] $0.01 \mathrm{M}$ usando agua bidestilada, y soluciones 0.001 y $0.0001 \mathrm{M}$ mediante diluciones sucesivas. El pH de las soluciones resultantes de $\mathrm{NaCl}$ 0, 0.0001, 0.001, $0.01 \mathrm{M}$ fue 5.21, 5.17, 5.08, 4.9 respectivamente. También se prepararon soluciones de $\mathrm{NaCl} 0.0001 \mathrm{M}$ a pH 9.67, 5.18 y 3.60.

Comparación de curvas de AFM con teoría continua de equilibrio y estabilidad coloidal. Las curvas de fuerza de acercamiento de AFM para el sistema substrato-microesfera fueron comparadas con curvas derivadas de la teoría continua clásica DLVO (Adamson y Gast 1997) existente para fuerzas intersuperficiales. La teoría incluye fuerzas de van der Waals y de doble capa eléctrica. Los parámetros que se necesitan son los de las superficies sólidas y del medio líquido en que las superficies interactúan. Mayores detalles sobre la modelación de fuerzas intersuperficiales se encuentran en el apéndice A.

\section{RESULTADOS Y DISCUSIÓN}

La figura 1c muestra una imagen SEM de un cantilever plano de nitruro de silicio modificado mediante una microesfera de vidrio de $20 \mu \mathrm{m}$ de diámetro en uno de sus extremos. Las imágenes muestran que el protocolo utilizado es óptimo en varios aspectos claves en la medición de fuerzas intersuperficiales, esto es, posición correcta de la microesfera respecto al cantilever, fijación suficientemente resistente como para que la microesfera no se suelte, que quedó comprobado al soportar la manipulación y vacío necesarios para obtener la imagen SEM de la figura 1c, y operación limpia sin contaminación de la superficie de la microesfera con adhesivo. Para un cantilever modificado similar al de la figura 1c se midió la constante elástica mediante el método basado en estándares de calibración. La constante de fuerza del cantilever modificado, utilizado aquí para las medidas de fuerza, resultó ser $0.14 \mathrm{~N} / \mathrm{m}$.

Las figuras 2a-d y 3a-d muestran imágenes AFM de superficies tridimensionales de substratos sin resina y con resina, respectivamente, con resolución creciente de $50 \times 50,30 \times 30,10 \times 10$, y $5 \times 5 \mu \mathrm{m}^{2}$. Las imágenes del substrato sin resina muestran una superficie más granular, porosa y aparentemente rugosa, que la del substrato recubierto con resina. La apariencia más lisa de la superficie con recubrimiento se debe a que la resina se deposita en parches o dominios lisos de tamaño bastante mayor al de los granos del substrato sin recubrimiento, sin embargo la profundidad de los valles entre dominios de resina y por tanto la rugosidad, puede llegar a ser de tamaño considerable. 


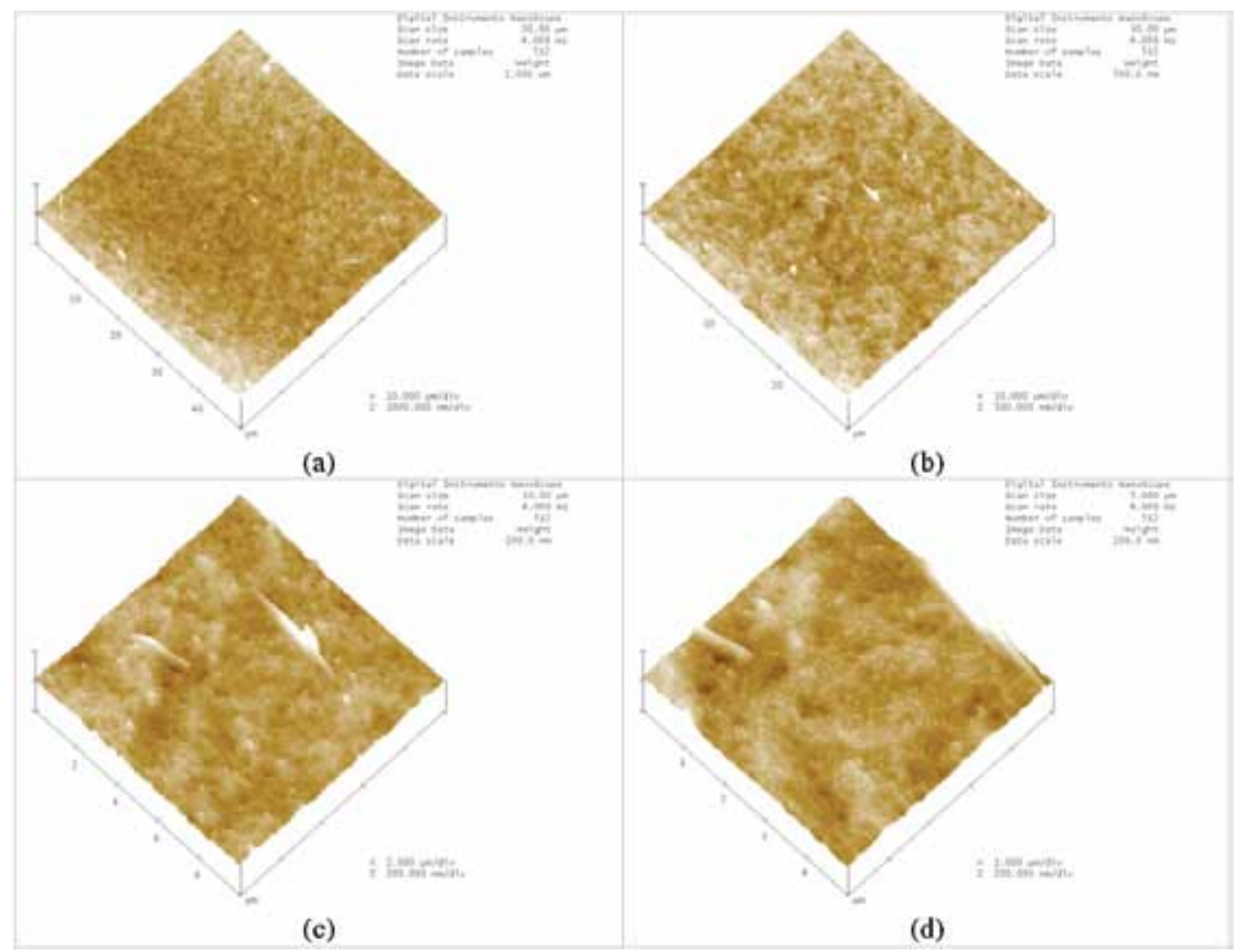

Figura 2. Imágenes AFM de substratos sin resina con resolución creciente de (a) $50 \times 50$, (b) $30 \times 30$, (c) $10 \times 10$, y (d) $5 \times 5 \mu \mathrm{m}^{2}$.

Una comparación de las imágenes de mayor resolución en la figura $2 \mathrm{c}$ vs. $3 \mathrm{c}$ y $2 \mathrm{~d}$ vs. $3 \mathrm{~d}$, pareciera respaldar esta idea. La tabla 1 resume resultados de mediciones de rugosidad RMS para ambos substratos, con y sin recubrimiento, sobre las imágenes de la figura 4. Las rugosidades se informan para una dirección $x$ arbitraria (figura 4, imágenes a y d), para la dirección $y$ perpendicular a $x$ (figura 4, imágenes b y e) y para toda la superficie (figura 4, imágenes $\mathrm{c}$ y f). Estos resultados indican precisamente que el substrato recubierto es más rugoso y que la resina se deposita en dominios extensos tipo meseta. Acuña (2007) presenta levantamientos topográficos AFM de la superficie de las microesferas de vidrio utilizadas en este estudio.

Tabla 1. Rugosidades $\mathrm{RMS}^{\dagger}$ de substratos sin recubrimiento y con recubrimiento de resina de madera.

\begin{tabular}{cccc}
\hline Substrato & RMS & RMS & RMS \\
& Dirección $\mathbf{x}$ & Dirección $\mathbf{y}$ & Area $\mathbf{x}-\mathbf{y}$ \\
Sin resina & 7.9 & 8.4 & 9.5 \\
Con resina & 9.1 & 14.5 & 14.4 \\
\hline
\end{tabular}

RMS: Raíz cuadrada del cuadrado de desviaciones medias. 


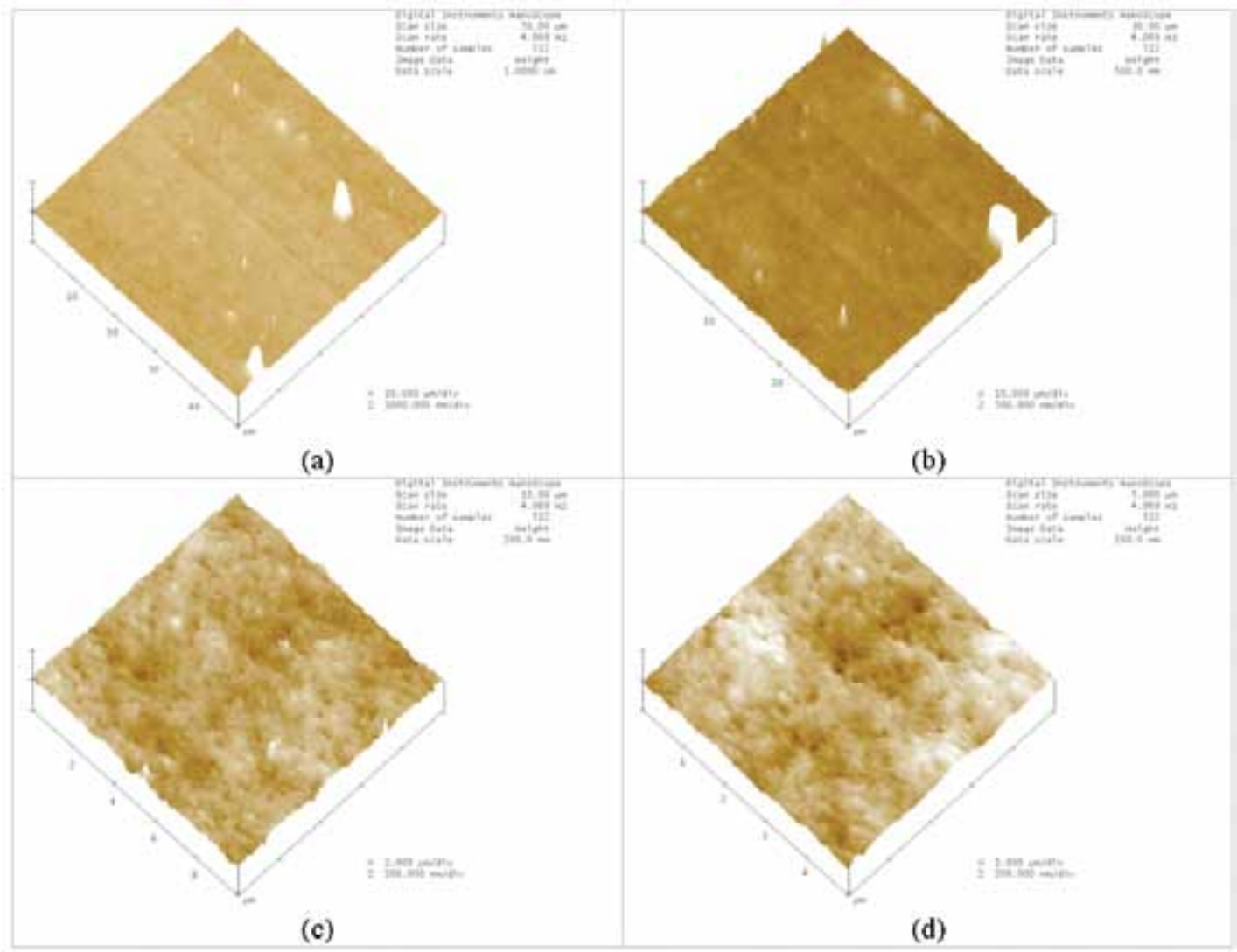

Figura 3. Imágenes AFM de substratos recubiertos con resina, resolución creciente de (a) $50 \times 50$, (b) $30 \times 30$, (c) $10 \times 10, y$ (d) $5 \times 5 \mu \mathrm{m}^{2}$.

Tabla 2. Ángulos de contacto de una gota de agua depositada sobre substratos sin recubrimiento y con recubrimiento de resina de madera. El ángulo se mide a través de la fase agua

\begin{tabular}{ccc}
\hline Substrato & $\begin{array}{c}\text { Angulo de contacto promedio } \\
\text { (grados) }\end{array}$ & $\begin{array}{c}\text { Desviación estándar } \\
\text { (grados) }\end{array}$ \\
\hline Sin resina & 69.4 & 2.1 \\
\hline Con resina & 42.6 & 2.9 \\
\hline
\end{tabular}

El ángulo de contacto ha sido ofrecido como el mejor indicador de la mojabilidad de una superficie sólida cuando se utilizan fluidos puros y superficies relativamente suaves. La tabla 2, resume los resultados de ángulos de contacto de equilibrio para una gota de agua bidestilada depositada sobre substratos sin recubrimiento y con recubrimiento de resina de madera. El ángulo se mide a través de la fase agua. El recubrimiento de resina reduce el ángulo de contacto en aproximadamente 30 grados, estableciéndolo en un valor cercano a 40 grados, haciendo con ello la superficie más hidrofílica, y verificando al pasar la hipótesis planteada en la Figura la para la orientación de las anfifilas de resina. Esta es la orientación que adopta la resina en el proceso de fabricación de papel, excepto que en ese caso la configuración es micelar, la geometría esférica y el tamaño coloidal. En ambos casos la carga superficial es negativa debido a la disociación de grupos polares que constituyen las cabezas de las anfifilas de resina. 
La figura 5 muestra curvas de fuerza AFM de acercamiento para el sistema microesfera de vidrio y substrato recubierto de resina de madera en agua y en soluciones $0,0.0001,0.001$ y $0.01 \mathrm{M}$ de $\mathrm{NaCl}$. Las superficies de vidrio están formadas principalmente por grupos $\mathrm{SiOH}$ que en contacto con soluciones acuosas tienden a disociarse formando aniones $\mathrm{SiO}^{-}$(Allen y Mativejić 1969). En tanto la superficie expuesta de substratos recubiertos de resina se encuentra conformada mayoritariamente por grupos carboxilos $\mathrm{COOH}$ que en contacto con soluciones acuosas tienden a disociarse dando origen a grupos $\mathrm{COO}^{-}$. Ambos grupos son responsables de cargar las superficies negativamente y producir repulsión a medida que las superficies se acercan una a otra (Eyzaguirre et al. 2004). En contacto con soluciones acuosas, ambos grupos aniónicos están disponibles para continuar la red de agua formando puentes hidrógeno.

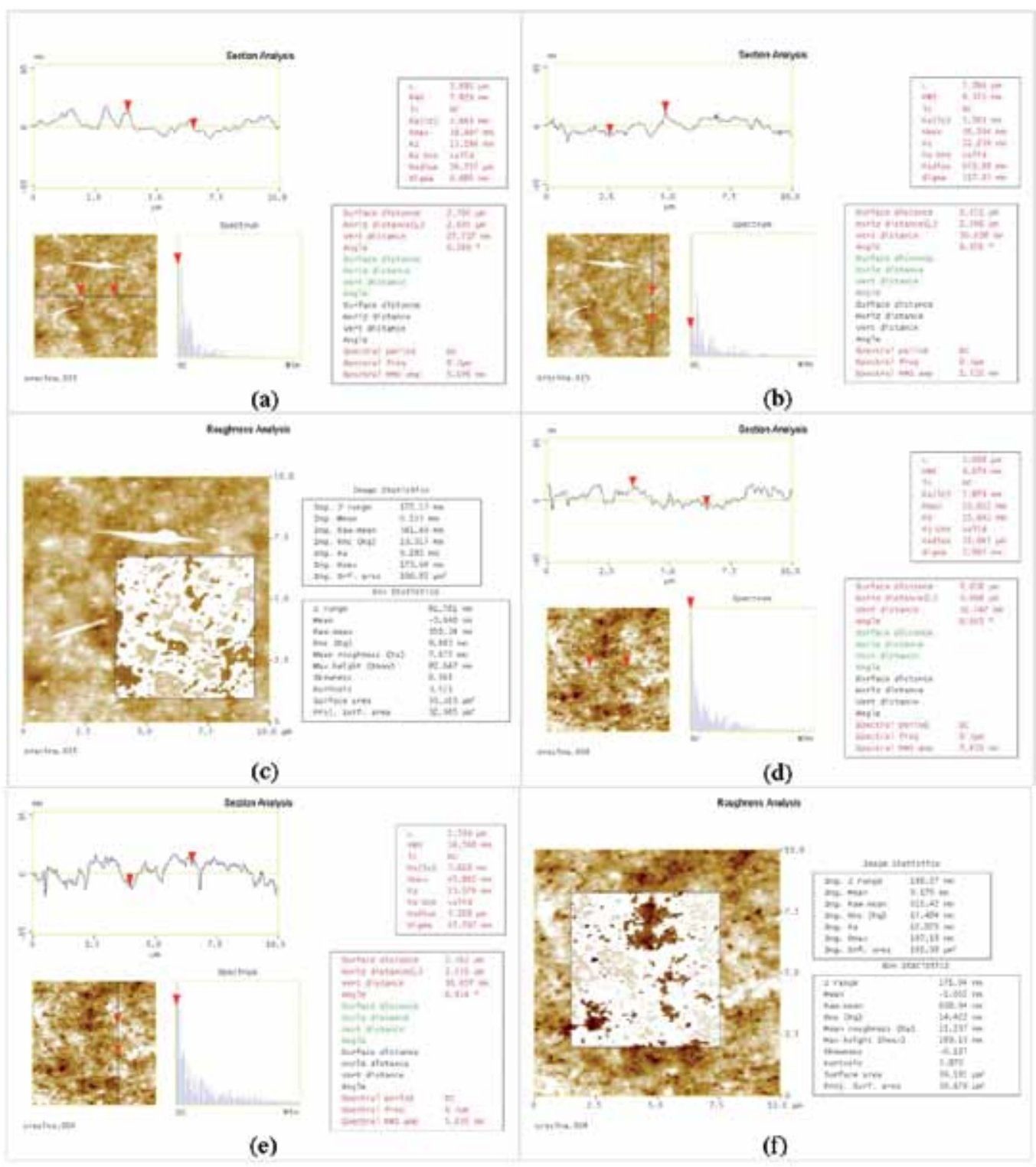

Figura 4. Perfiles de rugosidad y rugosidad media de substratos sin resina (a-c) y con resina (d-f).

El sistema microesfera de vidrio y substrato recubierto de resina es electrostáticamente equivalente al sistema micela de resina y fibra en la fabricación de papel y en la fabricación de celulosa, donde la repulsión entre micelas de resina y entre resina y fibra tiene su origen en la interacción de grupos superficiales $\mathrm{COO}^{-}$. Es esta repulsión la que mantiene a la resina dispersa en suspensión. La 
fijación óptima de la resina a fibras, objetivo en operaciones de control de pitch y dusting, requiere anular estas fuerzas repulsivas. Por el contrario, la maximización de estas fuerzas repulsivas es objetivo en la fabricación de celulosa libre de "pintas" de pitch y otras partículas coloidales. Los resultados para el sistema vidrio-resina sugieren una forma de hacerlo.

Las curvas de fuerza AFM de acercamiento para el sistema microesfera de vidrio y substrato recubierto de resina en las figuras 5 a a $5 \mathrm{~d}$ muestran que a medida que aumenta la concentración de electrolito en el medio fluido, disminuye la interacción entre las superficies; en otras palabras, a medida que la concentración de electrolito aumenta, la fuerza de repulsión entre ellas disminuye. La explicación es simple (Eyzaguirre et al. 2004); el electrolito se disocia en agua, los cationes neutralizan o apantallan las cargas negativas tanto en la superficie del vidrio como en la superficie de la resina expuesta de modo que los grupos aniónicos dejan de "verse", es el momento en que las fuerzas atractivas comienzan a hacerse más notorias. Las figuras $5 \mathrm{a}$ a $5 \mathrm{~d}$ muestran que a mayor concentración de electrolito mayor es el apantallamiento y por tanto menor es la repulsión entre las superficies.

Las figuras 5a a 5d muestran también el mejor ajuste para las curvas de fuerza AFM de acercamiento mediante la teoría DLVO clásica de equilibrio y estabilidad de sistemas coloidales. La tabla 3 resume los valores de potencial superficial que mejor ajustan los datos experimentales para la interacción resina-vidrio. Los resultados de la tabla 3 muestran que la resina desarrolla potenciales menores que el vidrio y que a medida que aumenta la concentración de electrolito la disminución del potencial superficial es más acelerada en la resina que en el vidrio, sugiriendo que la resina forma sales neutras. Los parámetros elegidos (Tabla A.1) permiten ajustar bien la interacción en el largo rango. A corto rango DLVO predice atracción, que es lo contrario a lo que ocurre en el sistema vidrioresina. La figura 5 muestra que estas superficies no entran en contacto íntimo, especialmente a baja concentración de electrolito. Esto se debe a que en la interacción de superficies hidrofílicas, como vidrio-resina y como resina-fibra, existen fuerzas repulsivas adicionales, no consideradas en la teoría DLVO clásica. Cuando dos superficies hidrofílicas en ambiente acuoso son obligadas a acercarse en el ámbito de lo que se denomina corto rango, menor a $5 \mathrm{~nm}$ de separación, el agua entre ellas maximiza la formación de puentes hidrógeno con las superficies cargadas. Esto produce una capa de hidratación, con agua en estado muy ordenado, con baja entropía y con viscosidad mayor que la del agua líquida, que impide el contacto íntimo entre las superficies. La fuerza utilizada para acercar las superficies produce un aumento de la repulsión, proporcional a la fuerza usada para acercarlas y las capas de agua entre las superficies sólidas son evacuadas o exprimidas una a una del espacio intersuperficial. Estas fuerzas repulsivas, que sólo en las últimas décadas han comenzado a ser discutidas en la literatura (Israelachvili 1992), son oscilatorias y de muy corto rango. Acuña y Toledo (2008) muestran datos que avalan el fenómeno de hidratación y de la evacuación de agua estructural. En el corto rango las fuerzas de hidratación sobrepasan a las fuerzas electrostáticas y las enmascaran.

Tabla 3. Tipo de electrolito, concentración real y ajustada, $\mathrm{pH} \sim 5.0$, valores de $\psi_{0, \text { silice }}$ de Tabla A.1, y valores de $\psi_{0, \text { resin } a}$ provenientes del mejor ajuste del modelo de carga constante para la interacción de superficies disimilares a los datos experimentales de fuerzas AFM en la figura 5.

\begin{tabular}{|c|c|c|c|c|}
\hline Electrolito & Concentración real (M) & Concentración (M) & $(\mathrm{mV})$ & $(\mathrm{mV})$ \\
\hline $\begin{array}{c}\text { Agua } \\
\text { bidestilada }\end{array}$ & $\sim 0$ & $1.0 \times 10^{-5}$ & -118.0 & -102.0 \\
\hline & $1 \times 10^{-4}$ & $1.0 \times 10^{-4}$ & -74.6 & -31.0 \\
\hline $\mathrm{NaCl}$ & $\begin{array}{l}1 \times 10^{-3} \\
1 \times 10^{-2}\end{array}$ & $\begin{array}{l}7.0 \times 10^{-4} \\
4.0 \times 10^{-3}\end{array}$ & $\begin{array}{l}\psi_{0, \text { silice }}-55.4 \\
-51.3\end{array}$ & $\begin{array}{r}\psi_{0, r e \sin a}-10.0 \\
-6.0\end{array}$ \\
\hline
\end{tabular}

La figura 6a muestra una comparación de las curvas de fuerza AFM de acercamiento para el sistema microesfera de vidrio y substrato recubierto de resina en solución de $\mathrm{NaCl}$ a distintas concentraciones. Esta figura muestra claramente que la fuerza diverge en agua bidestilada revelando (i) una fuerza repulsiva de corto rango que excede la repulsión electrostática, esta fuerza es conocida 
como estructural, de solvatación o de hidratación, (ii) que a medida que aumenta la concentración de electrolito la fuerza repulsiva disminuye y (iii) que a altas concentraciones de electrolito la fuerza es más susceptible a ser modelada mediante fuerzas de largo rango (DLVO) solamente. Para el sistema resina-fibra en la fabricación de papel y celulosa, la presencia de electrolitos en una justa medida es clave para la fijación de la resina en el caso del papel y dispersión de la resina en el caso de la celulosa; sin embargo, un exceso de electrolito puede conducir al colapso del sistema micelar y a la separación de la resina en una nueva fase.

De acuerdo a los resultados obtenidos para las fuerzas AFM de acercamiento para el sistema microesfera de vidrio-resina, los resultados para las curvas AFM de alejamiento debieran mostrar adhesiones débiles y sólo a concentraciones altas de electrolito, principalmente debido a que las curvas de acercamiento no presentan saltos de contacto. Esto es así de acuerdo al resumen comparativo en la figura 6b. La interacción en agua pura y en soluciones de muy baja concentración de electrolitos es de carácter tan repulsivo que la adhesión entre ellas no es posible. Sin embargo, para concentraciones más altas de electrolito la repulsión disminuye apreciablemente haciendo posible el contacto adhesivo. La figura $6 \mathrm{~b}$ muestra que la curva de alejamiento para este sistema a una concentración de $\mathrm{NaCl} 0.01$ M presenta valores de adhesión significativos, del orden de $10 \mathrm{nN}$ (con $F / R=-0.5 \mathrm{mN} / \mathrm{M}$, el mínimo de la curva de fuerza, y $R=20 \mathrm{~m}$, el radio de la microesfera utilizada). La correlación encontrada entre concentración de electrolito y adherencia es nueva y actualmente la verificamos para otras superficies.

La figura 7 muestra resultados de fuerzas AFM de acercamiento para el sistema microesfera de vidrio y substrato de vidrio hidrofobizado y recubierto con resina en ambiente fluido caracterizado por diversos electrolitos y diversas concentraciones. Los resultados muestran claramente que las fuerzas son repulsivas y que disminuyen notablemente con la concentración y el tamaño del electrolito.

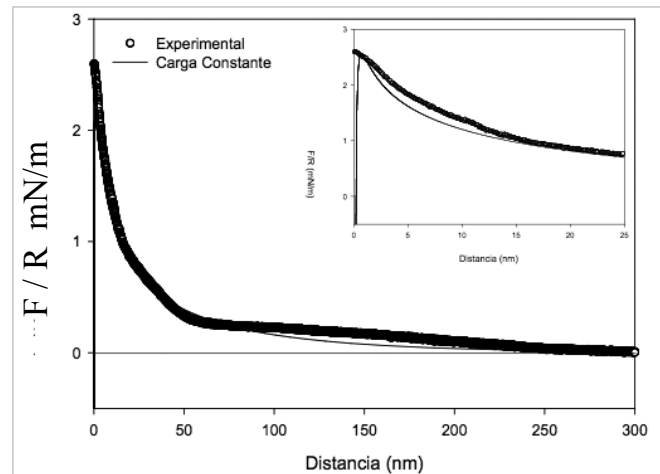

(a)

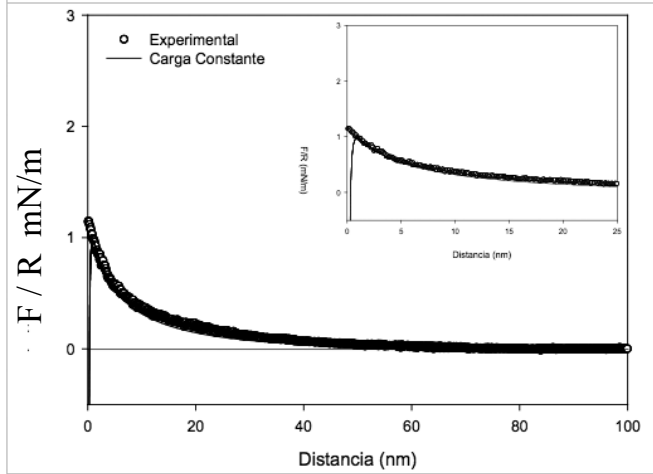

(c)

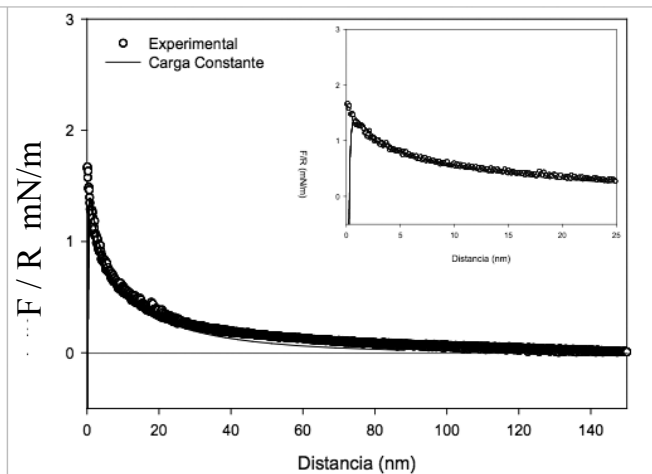

(b)

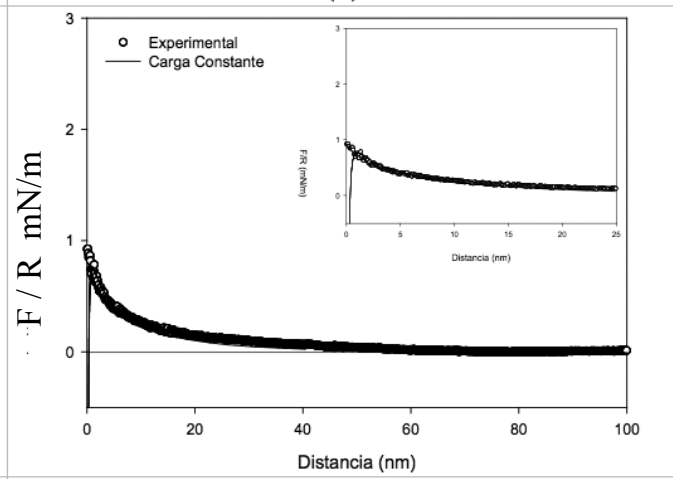

(d)

Figura 5. Curvas de fuerza AFM de acercamiento para el sistema microesfera de vidrio y substrato recubierto de resina de madera en (a) agua, (b) en solución de $\mathrm{NaCl} 0.0001 \mathrm{M}$, (c) en solución de $\mathrm{NaCl} 0.001 \mathrm{M}$ y (d) en solución de $\mathrm{NaCl} 0.01 \mathrm{M}$ (ocho réplicas). Las líneas continuas en las curvas de acercamiento muestran el mejor ajuste obtenido usando teoría DLVO. 


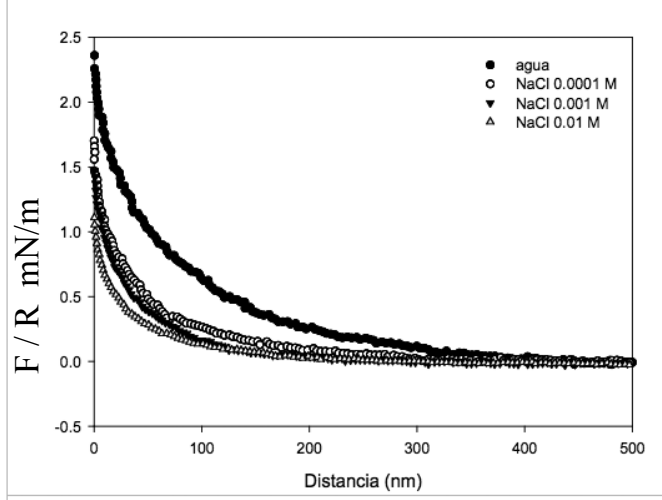

(a)

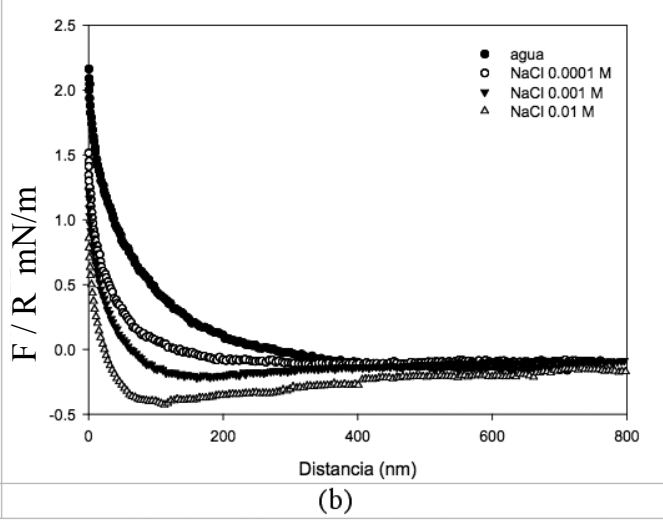

(b)

Figura 6. Comparación de curvas de fuerza AFM de acercamiento (a) y alejamiento (b) para el sistema microesfera de vidrio y substrato recubierto de resina de madera en solución de $\mathrm{NaCl}$ a distintas concentraciones.

En general, las ventanas de variables de operación tanto en la fabricación de papel como de celulosa son estrechas imponiendo rangos modestos para la variación de concentración de electrolitos y principalmente $\mathrm{pH}$. Esta limitación hace necesaria la adición de fijadores en el caso del papel y dispersantes en el caso de la celulosa. Los resultados de un estudio sobre el efecto de fijadores y dispersantes sobre las curvas de fuerza de acercamiento y alejamiento para el sistema fibra-resina serán publicados próximamente.

En la fabricación de papel y celulosa las fuerzas adhesivas entre resina y fibra pueden ser aumentadas o disminuidas respectivamente de manera considerable a $\mathrm{pH}$ adecuado y mediante la acción de fijadores y dispersantes respectivamente. La figura 8 muestra el efecto del $\mathrm{pH}$ sobre las curvas AFM de acercamiento para el sistema microesfera de vidrio y substrato de vidrio hidrofobizado y recubierto de resina. A mayor $\mathrm{pH}$ mayor disociación de grupos carboxilos en la resina y por tanto mayor densidad de carga superficial lo que trae por consecuencia una mayor repulsión. Así, en términos aplicados, $\mathrm{pH}$ altos favorecen la repulsión entre micelas de resina y entre micelas de resina y fibra y por tanto la dispersión de la resina. 


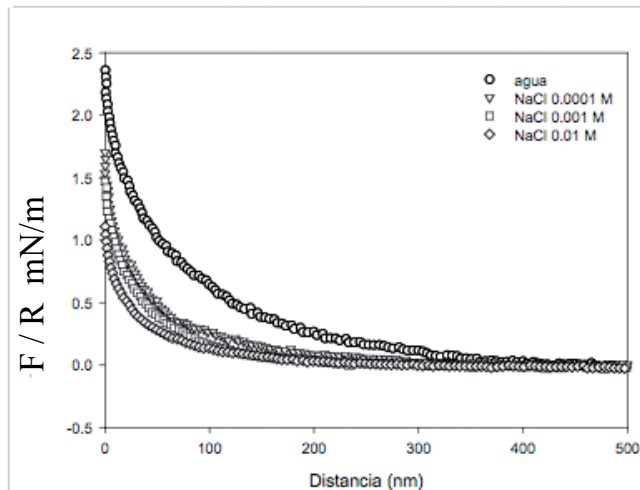

(a)

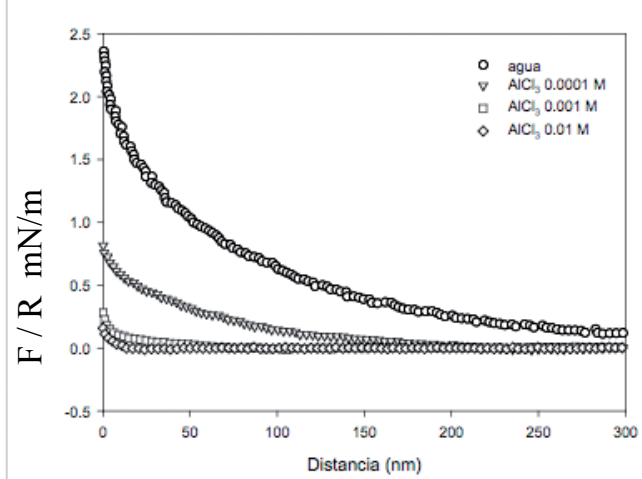

(c)

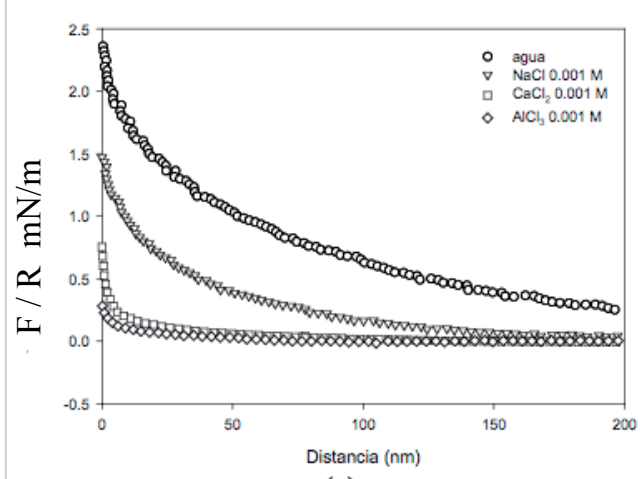

(e)

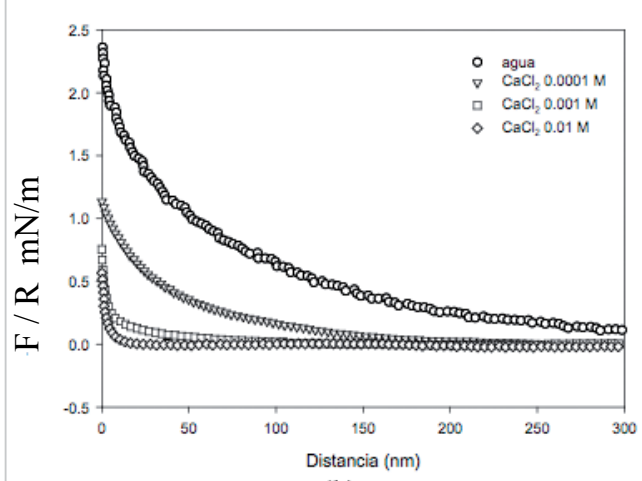

(b)

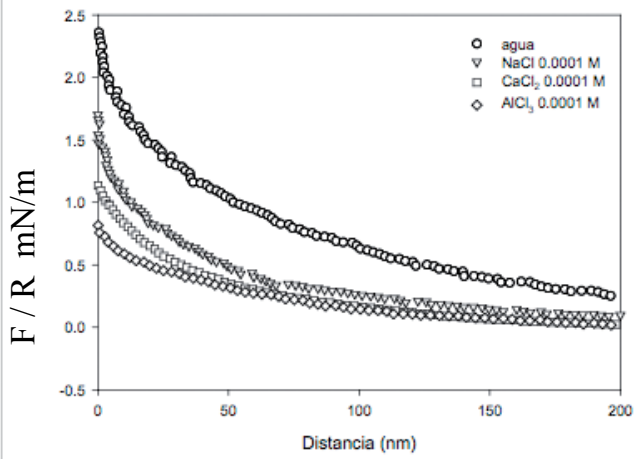

(d)

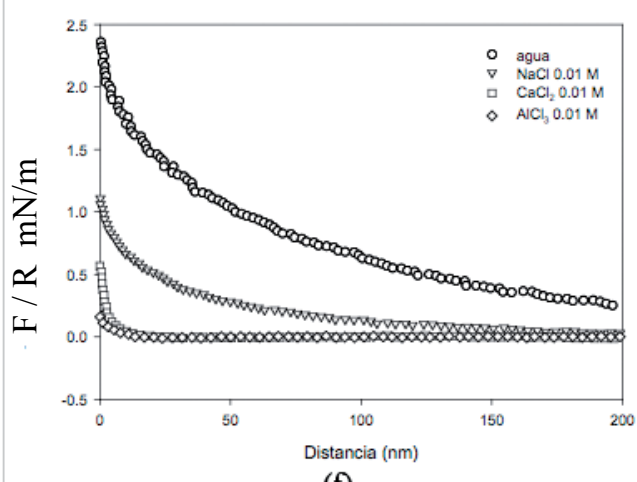

(f)

Figura 7. Curvas de fuerza AFM de acercamiento para el sistema microesfera de vidrio y substrato recubierto de resina de madera en solución de distintos electrolitos y a distintas concentraciones.

En este caso el substrato es vidrio plano silanizado y recubierto de resina. (a) $\mathrm{NaCl}$ distintas concentraciones, (b) $\mathrm{CaCl}_{2}$ distintas concentraciones, (c) $\mathrm{AlCl}_{3}$ distintas concentraciones, (d) 0.0001 $\mathrm{M}$, distintos electrolitos, (d) $0.001 \mathrm{M}$, distintos electrolitos, (d) $0.01 \mathrm{M}$, distintos electrolitos. 


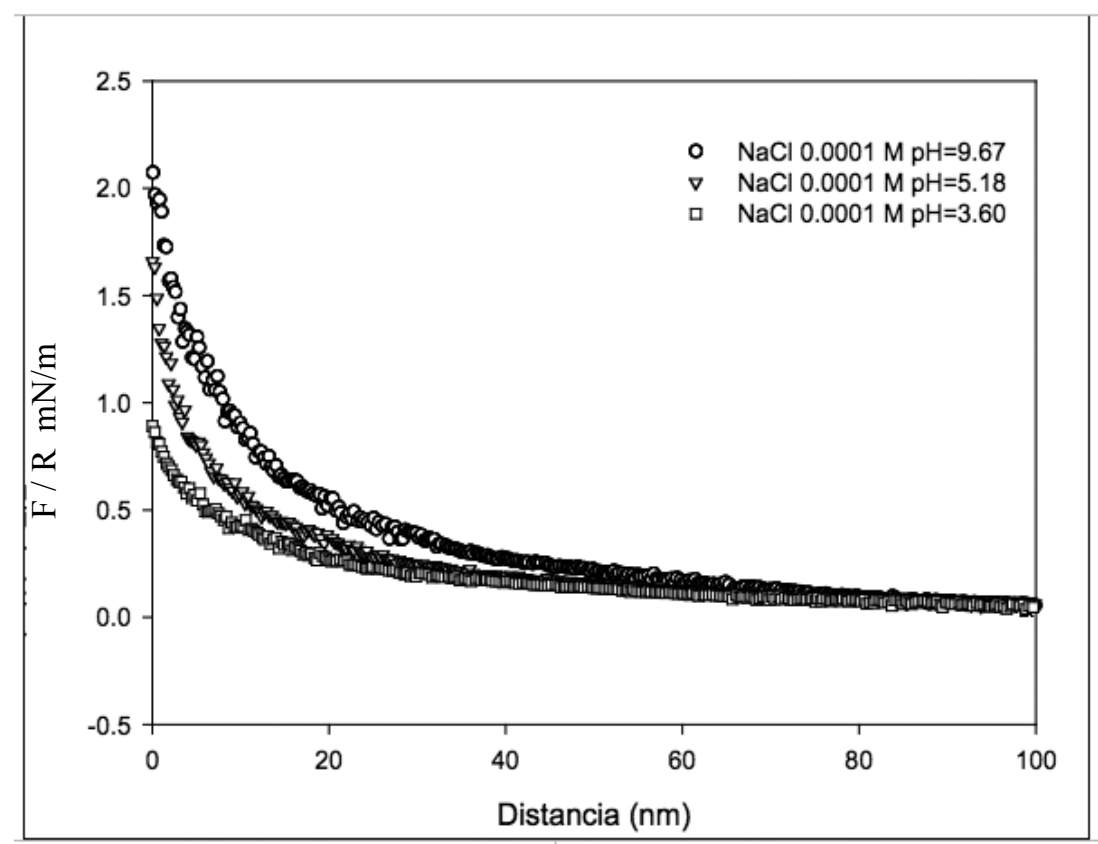

Figura 8. Curvas de fuerza AFM de acercamiento para el sistema microesfera de vidrio y substrato recubierto de resina de madera en solución $0.0001 \mathrm{M}$ de $\mathrm{NaCl}$ a distintos $\mathrm{pH}$. En este caso el substrato es vidrio plano silanizado y recubierto de resina.

Nuestros resultados son novedosos a juzgar por la escasa información que existe en la literatura y son técnicamente relevantes a juzgar por las aplicaciones que se benefician. Una vez explicados sistemática y consistentemente debieran ser un aporte a la comprensión fisicoquímica del equilibrio y estabilidad de sistemas coloidales de interés en ciencia y tecnología, en particular en la fabricación, almacenamiento y uso de papel y en la fabricación de celulosa.

\section{CONCLUSIONES}

Las medidas de ángulos de contacto de una gota de agua sobre substratos recubiertos de resina revelaron superficies más hidrofílicas, verificando la hipótesis planteada sobre orientación de las anfifilas de resina con colas alifáticas ancladas en el substrato hidrofóbico y cabezas polares extendiéndose hacia el fluido ambiente. Las medidas de fuerzas se interpretaron a la luz del balance de fuerzas atractivas -van der Waals- y repulsivas -electrostáticas- de la teoría continua clásica de fuerzas para sistemas coloidales. Las medidas muestran una fuerte y persistente fuerza repulsiva de muy corto rango, que excede la repulsión electrostática, a distancias de separación menores a 100 Å. Esta fuerza que no es explicada por la teoría clásica de fuerzas coloidales tiene su origen en un marcado ordenamiento molecular del agua en la vecindad de las superficies eléctricamente cargadas y actúa como barrera estérica al contacto entre ellas. El tamaño de la barrera y la intensidad de la fuerza repulsiva dependen de la magnitud de la carga eléctrica en las superficies, que a su vez depende de su composición química y de las características de la solución líquida que las rodea. Esta fuerza repulsiva disminuye a medida que aumenta la concentración y el tamaño del electrolito en el medio fluido debido a apantallamiento de las cargas en las superficies. De acuerdo a estos resultados, en la fabricación de papel las fuerzas adhesivas entre resina y fibra pueden ser aumentadas de manera considerable aumentando la fortaleza iónica y disminuyendo el pH de la pulpa y mediante la acción de fijadores. Por el contrario, en la fabricación de celulosa las fuerzas adhesivas entre resina y fibra pueden ser disminuidas y anuladas en su totalidad disminuyendo la fortaleza iónica y aumentando el pH de la pulpa y mediante la acción de dispersantes. 


\section{AGRADECIMIENTOS}

Los autores agradecen el apoyo financiero de Conicyt a través del Proyecto Fondecyt 1090781, al Proyecto DIUBB 086022 2/R y a Papeles Norske Skog Bío Bío por facilitar la resina utilizada en este trabajo.

\section{REFERENCIAS}

Acuña, S.M. 2007. Medición directa de fuerzas superficiales y adhesivas mediante microscopía de fuerza atómica e interpretación a la luz de teorías continua y semicontinua. Aplicación a minerales, metales y productos de la madera. Tesis Doctorado en Ciencias de Ingeniería Química, Universidad de Concepción, Concepción, Chile.

Acuña, S.M.; Toledo, P.G. 2008. Short-Range Forces between Glass Surfaces in Aqueous Solutions. Langmuir (24): 4881-4887.

Adamson, A.W.; Gast, A.P. 1997. Physical Chemistry of Surfaces. Wiley Interscience, New York.

Allen, L.H.; Matijevic, E. 1969, Stability of colloidal silica I. Effect of simple electrolytes. J. Colloid and Interface Sci. 31: 287-296.

Binning, G.; Rhoer, H.; Gerber, CH.; Weibel, E. 1982. Surface studies by scanning tunneling microscopy. Physical Review Letters 49(1): 57-60.

Binning, G.; Quate, F.; Gerber, CH. 1986. Atomic force microscope. Physical Review Letters 56(9): 930-933.

Bowen, W.; Lovitt, R.; Wright, C. 2001. Atomic force microscopy study of the adhesion of Saccharomices cerveseae. J. Colloid Interface Sci. 237: 54-61.

Bowen, W.; Lovitt, R.; Wright, C. 2000. Direct quantification of Aspergillus niger spore adhesion in liquid using an atomic force microscopy. J. Colloid Interface Sci. 228: 428-433.

Chen, X.; Davies, M.C.; Roberts, C.J.; Tendler, S.J.B.; Williams, P.M. 1997. Recognition of protein adsorption onto polymer surfaces by scanning force microscopy and probe-surface adhesion measurements with protein-coated probes. Langmuir 13: 4106-4111.

Díaz, S.A. 2005. Flujo y transporte en materiales porosos: construcción de micromodelos transparentes. Memoria de Título, Departamento de Ingeniería Química, Facultad de Ingeniería, Universidad de Concepción, Concepción, Chile.

Dufrêne, Y., Barger, W., Green, J-B., Lee, G. 1997. Nanometer-scale surface properties of mixed phospholipid monolayers and bilayers. Langmuir 13: 4779-4794.

Eyzaguirre, C.S.; Toledo, P.G.; Cariñanco, M.; Rivera, G. 2004. Efeito da estabilidade colloidal de resina da madeira na fabricação de papel de impressão e uso de potencial zeta como indicador. $O$ Papel 10.73p

Fengel, D.; Wegener, G. 1989. Extractives. In: Wood Chemistry, Ultrastructure, Reactions. Walter de Gruyter, Berlin, 182-226.

Freire, C.S.R.; Silvestre, A.J.D.; Pascoal Neto, C. 2005. Lipophilic extractives in Eucalyptus globulus Kraft pulps. Behaviour during ECF bleaching. J. Wood Chem. Technol. 25: 67-80. 
Gutiérrez, A.; Del Río, J.C. 2003. Lipids from flax fibers and their fate in alkaline pulping. J. Agric. Food Chem. 51: 4965-4971.

Gutiérrez, A.; Del Río, J.C. 2005. Chemical characterization of pitch deposits produced in themanufacturing of high-quality paper pulps from hemp fibers. Bioresour. Technol. 96: 1445-1450.

Gutiérrez, A.; Del Río, J.C.; González-Vila, F.J.; Martín, F. 1998. Analysis of lipophilic extractives from wood and pitch deposits by solid-phase extraction and gas chromatography. J. Chromatogr. A. 823: 449-455.

Israelachvili, J.N.; Adams, G.E. 1976. Direct measurement of long range forces between two mica surfaces in aqueous $\mathrm{KNO}_{3}$ solutions. Nature 262: 774-776.

Israelachvili, J. 1992. Intermolecular and Surface Forces. Academic Press, Segunda Edición, 1992.

Koheler, J.A.; Ulbricht, M.; Belfort, G. 2000. Internolecular forces between a protein and a hydrophilic modified polysulfone film with relevance to filtration. Langmuir 16: 4162-4171.

Lee, G.U.; Chrisey, L.; Colton, R.J. 1994. Direct measurement of the forces between complementary strands of DNA. Science 266: 771-773.

Micic, M.; Benitez, I.; Ruano, M.; Mavers, M.; Jeremic, M.; Ratotic, K.; Moy, V.; Leblanc, R. 2001. Probing the lignin nanomechanical properties and lignin-lignin interactions using the atomic force microscopy. Chem. Phys. Lett. 347: 41-45.

Ong, Y-L.; Razatos, A.; Georgiou, G.; Sharma, M. 1999. Adhesión forces between E. coli bacteria and biomaterial surfaces. Langmuir 15: 2719-2725.

Richter, R.P.; Bérat, R. ; Brisson, A.R. 2006. Formation of solid-supported lipid bilayers: An integrated view. Langmuir 22: 3497-3505.

Rundlöf, M.; Karlsson, M.; Wågberg, L.; Poptoshev, E.; Rutland, M.; Claesson, P.M. 2000. Application of the JKR method of the measurement of adhesion to Langmuir-Blodgett cellulose surfaces. J. Colloid Interface Sci. 230: 441-447.

Schönherr, H.; Johnson, J.M.; Lenz, P. 2004. Vesicle adsorption and lipid bilayer formation on glass studied by atomic force microscopy. Langmuir 20: 11600-11606.

Silvestre, A.J.D.; Pereira, C.L.C.; Pascoal Neto, C.; Duarte, A.C.; Cavaleiro, J.A.S.; Furtado, F.P. 1999. Chemical composition of pitch deposits from an ECF Eucalyptus globulus bleached kraft pulp mill: its relationship with wood extractives and additives in process streams. Appita J. 52 (5): 375-382.

Zauscher, S.; Klingenberg, D. 2000. Normal forces between cellulose surfaces measured with colloidal probe microscopy. J. Colloid Interface Sci. 229: 497-510.

\section{Apéndice A}

Modelación de curvas de fuerza de acercamiento entre superficies de vidrio y resina

La modelación de las fuerzas de interacción entre vidrio y resina mediante teoría DLVO clásica continua y semicontinua enfrenta dificultades. Las superficies son disimilares, el vidrio se disocia superficialmente de acuerdo al equilibrio $\mathrm{SiOH} \leftrightarrow \mathrm{SiO}^{-}+\mathrm{H}^{+}$, y la resina de acuerdo al equilibrio $\mathrm{R}-\mathrm{COOH} \leftrightarrow \mathrm{R}-\mathrm{COO}^{-}+\mathrm{H}^{+}$, el resultado es que bajo condiciones dadas de $\mathrm{pH}$ y fortaleza iónica 
ambas superficies adoptan potencial y carga superficial diferentes. Por otra parte, las interacciones estudiadas aquí ocurren en soluciones acuosas de $\mathrm{NaCl}, \mathrm{CaCl}_{2}$ y $\mathrm{AlCl}_{3}$ y por tanto aparece la dificultad adicional de electrolitos no simétricos. Así, la modelación de las fuerzas de interacción vidrio-mica se debe realizar mediante el concepto de Grupo Superficial Ionizable (ISG, del inglés Ionizable Surface Group) desarrollado por Levine y Smith $(1971)^{3}$, Smith $(1973)^{4}$, Healy y White $(1978)^{5}$, Hunter $(1981)^{6}$ y James y Parks $(1982)^{7}$, que ha sido utilizado con éxito para explicar las propiedades de doble capa eléctrica de arcillas, óxidos inorgánicos, coloides de polímero latex y biosuperficies en soluciones acuosas de electrolitos. De acuerdo a la teoría DLVO la presión entre superficies de vidrio y resina (su extremo polar disociable) en solución acuosa tiene origen en dos tipos de fuerzas, una fuerza de doble capa eléctrica, casi siempre repulsiva y una fuerza de London-van der Waals, casi siempre atractiva. La energía total de interacción entre las superficies a una cierta distancia de separación se obtiene por simple integración de la presión en el rango de interacción de interés. Así,

$$
V(L)=V_{v d W}(L)+V_{d c e}(L)
$$

resume la teoría DLVO clásica, donde $V_{v d W}$ es el potencial de interacción de London-van der Waals, $V_{d c e}$ el potencial de interacción de doble capa eléctrica y $L$ la distancia entre las superficies.

\section{Potencial de interacción entre superficies de vidrio y resina}

En la ecuación (A.1) para superficies disimilares como vidrio y resina y para electrolito asimétrico

$$
V_{v d W}(L)=-\frac{A}{12 \pi L^{2}}
$$

donde $A$ es la constante de Hamaker (J) sin retardo y efectiva para vidrio y resina, y

$$
V_{d c e}(L)=\frac{2 n k T}{\kappa}\left[2 \bar{y} \ln \left(\frac{B+\bar{y} \operatorname{coth}(\kappa L / 2)}{1+\bar{y}}\right)-\ln \left(\bar{y}^{2}+\cosh (\kappa L)+B \sinh (\kappa L)+\kappa L\right)\right]
$$

donde

$$
\bar{y}=\left(y_{1}+y_{2}\right) / 2 ; B=\left[1+\bar{y}^{2} \operatorname{csch} h^{2}(\kappa L / 2)\right]^{/ 2}
$$

$\kappa$ es la longitud de Debye (m), $y_{1}$ e $y_{2}$ son los potenciales eléctricos para superficies aisladas, en nuestro caso para superficies aisladas de vidrio y resina y $y_{i}=e \psi_{i} / k T$. La ecuación (A.3) se debe a Gregory $(1975)^{8}$ y corresponde a un modelo de carga superficial constante. Cuando los potenciales superficiales son idénticos entonces la ecuación (A.3) se reduce a la expresión para

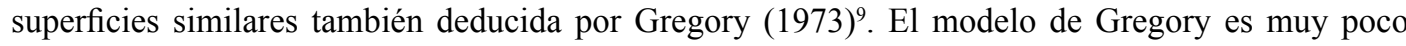
usado a pesar que compara muy bien con datos exactos de simulación para superficies disimilares con carga constante y del mismo signo.

La modelación aquí finalmente se ha implementado de la siguiente manera. El valor del potencial superficial a separación infinita para sílice, $\psi_{0, \text { vidrio, }}$, para cada $\mathrm{pH}$ se obtiene mediante DLVO con regulación de carga, ver más abajo. Los valores de $\psi_{0 \text {,vidrio }}$ calculados se resumen en la tabla 3.

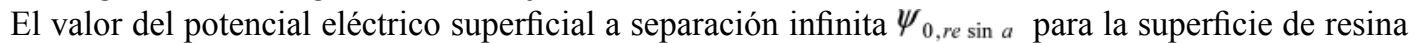
se obtiene del mejor ajuste de la Ecuación A.1 con A.2 y A.3 a los datos experimentales mediante AFM. Los resultados para $\psi_{0, \text { re sin } a}$ se muestran en la tabla 3. Es bueno recordar que los resultados

\footnotetext{
${ }^{3}$ Levine, S.; Smith, A.L. 1971, Theory of the differential capacity of the oxide/aqueous electrolyte interface. Discuss. Faraday Soc. 52: 290-301.

${ }^{4}$ Smith, A.L. 1973. En G.D. Parfitt (Ed.) Dispersion of Powders in Liquids, 2da. Ed. Applied Science Publishers, Barking, 86.

${ }^{5}$ Healy, T.W., White, L.R. 1978. Ionizable surface group models of aqueous interfaces. Adv. Colloid Interface Sci. 9: 303-345.

${ }^{6}$ Hunter, R.J. 1981. Zeta Potential in Colloid Science, Principles and Applications (1981), Academic New York, New York, 258-304

${ }^{7} J a m e s$, R.D.; Parks, G.A. 1982. En E. Matijevic (Ed.), Surface and Colloid Science, Vol. 12, Plenum, New York, 119-216.

${ }^{8}$ Gregory, J. 1975. Interaction of unequal double layers at constant charge, J. Colloid Interface Sci. 51: 44-51.

${ }^{9}$ Gregory, J. 1973. Approximate expression for the interaction of diffuse electrical double layers at constant charge, J. Chem. Soc. Faraday II 69: 1723-1728
} 
experimentales obtenidos mediante AFM son normalizados dividiendo el valor de fuerza $F$ medida por el radio $R$ de la microesfera usada en la medición, esto es, $F / R$. Por otro lado, la aproximación de Derjaguin $(1934)^{10}$ para la conversión de fuerza de interacción esfera-plano a potencial de interacción plano-plano es

$$
F(L)_{\text {esfera }}=2 \pi R V(L)_{\text {planos }}
$$

de modo que el potencial eléctrico de interacción total teórico (DLVO) calculado debe ser multiplicado por el factor $2 \pi$ a fin de comparar correctamente con datos $F / R$ experimentales de AFM.

\section{Potencial superficial interfase vidrio/agua}

La ecuación de Poisson-Boltzmann para el caso de placas idénticas en solución de electrolito simétrico 1:1 (que corresponde al caso más sencillo), usando la condición de borde de regulación de carga eléctrica puede, al igual que en los casos de potencial eléctrico constante y carga eléctrica constante, puede ser resuelto en forma analítica mediante el empleo adecuado de integrales elípticas. A continuación se presenta la teoría existente para la interacción de dos superficies planas idénticas inmersas en una solución de electrolitos asimétricos para el caso de regulación de carga. Como base de este análisis se utiliza un desarrollo previo de Chan $(2002)^{11}$.

Si se consideran dos superficies planas idénticas, uniformemente cargadas, localizadas a $x=-L / 2$ y a $x=L / 2$ (separadas a una distancia $L$ ) inmersas en una solución de electrolitos que comprende $n_{i}$ iones por unidad de volumen de la especie $i$ con valencia $v_{i}$, como lo indica la Figura A.1, el potencial electrostático está dado por la ecuación no lineal de Poisson-Boltzmann

$$
\nabla^{2} \psi=-\frac{e \rho}{\varepsilon \varepsilon_{0}}
$$

en esta ecuación, $\Psi$ corresponde al potencial eléctrico superficial, $e$ a la carga protónica, $\rho$ a la densidad de carga eléctrica superficial, $\varepsilon$ a la constante dieléctrica del medio y $\varepsilon_{0}$ a la permitividad del espacio vacío. De la ecuación de Boltzmann, la densidad de carga está definida por

$$
\rho=\sum_{i} v_{i} n_{i 0} \exp \left(-\frac{v_{i} e \psi}{k T}\right)
$$

en esta expresión la constante $k$ corresponde a la constante de Boltzmann y $T$ a la temperatura absoluta.

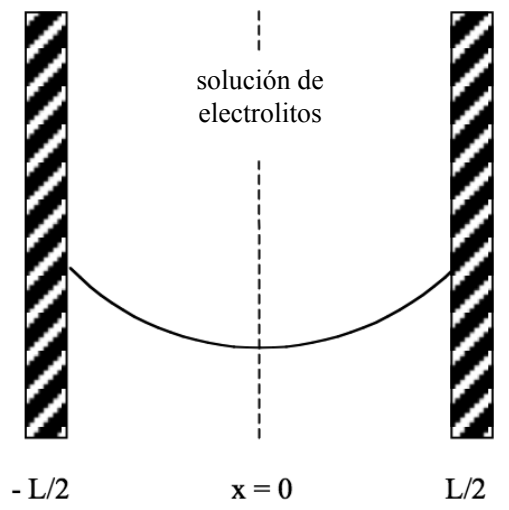

Figura A.1. Problema de interacción de dos superficies planas iguales en una solución de electrolitos.

Si consideramos que las superficies son infinitas, entonces la ecuación (A.6) puede escribirse en forma unidimensional como

\footnotetext{
${ }^{10}$ Derjaguin, B.V. 1934. Untersuchungen über die reibung und adhäsion, IV, Kolloid Zeitung 69: 155-164.

${ }^{11}$ Chan, D. 2002. A simple algorithm for calculating electrical double layer interactions in asymmetric electrolytes-Poisson-Boltzmann theory, J. Colloid Interface Sci. 245: 307-310.
} 


$$
\frac{d^{2} \psi}{d x^{2}}=-\frac{e}{\varepsilon \varepsilon_{0}} \sum_{i} v_{i} n_{i 0} \exp \left(-\frac{v_{i} e \psi}{k T}\right)
$$

Definiendo

$$
y=\frac{e \psi}{k T}, \quad n_{0}=\sum_{j} n_{j} v_{j}^{2}, \quad \alpha_{i}=\frac{n_{i}}{n_{0}}, \quad \kappa=\sqrt{\frac{e^{2} n_{0}}{\varepsilon \varepsilon_{0} k T}}, \quad \xi=\kappa x
$$

donde $y$ corresponde al potencial adimensional, $n_{0}$ a la fuerza iónica del medio, $\alpha_{i}$ es la razón de número de iones, $\kappa$ es la longitud de Debye y $\xi$ es la longitud adimensional, es posible escribir la Ecuación (A.8) como

$$
\frac{d^{2} y}{d \xi^{2}}=-\sum_{i} \alpha_{i} v_{i} \exp \left(-v_{i} y\right)
$$

que corresponde a la forma adimensional de la ecuación de Poisson-Boltzmann.

El potencial eléctrico escalado superficial en cada placa es $y(\kappa L / 2)=\mathrm{z}$. En el plano medio, $x=0$ y por simetría $d y / d x=0$. Si se define $u$ como el potencial eléctrico adimensional en el plano medio, entonces $y(0)=u$. Entonces, sin pérdida de generalidad se puede suponer que $z \geq u \geq 0$.

Integrando la ecuación (A.10) una vez y aplicando la condición de borde que en el plano medio $\xi=0, d y / d x=0$, la ecuación queda como

$$
\frac{d y}{d x}=\sqrt{2}\left(\sum_{i} \alpha_{i}\left(\exp \left(-v_{i} y\right)-\exp \left(-v_{i} u\right)\right)\right)^{1 / 2}
$$

La que puede ser integrada para obtener

Usando la identidad

$$
\kappa L=\sqrt{2} \int_{u}^{z} \frac{d y}{\left(\sum_{i} \alpha_{i}\left(\exp \left(-v_{i} y\right)-\exp \left(-v_{i} u\right)\right)\right)^{1 / 2}}
$$

$$
e^{-x}-e^{-y}=-2 e^{-(x-y) / 2} \operatorname{senh}((x-y) / 2)
$$

es posible escribir la ecuación (A.12) como

$$
\kappa L=\int_{u}^{z} \frac{d y}{\left(-\sum_{i} \alpha_{i}\left(e^{-v_{i}(y+u) / 2} \operatorname{senh}\left(v_{i}(y-u) / 2\right)\right)\right)^{1 / 2}}
$$

Definiendo una nueva variable de integración, $s$, definida por $y=s^{2}+u$ y sabiendo qué cuando

$$
\begin{gathered}
y=u, s=0 \\
y=z, s=\sqrt{z-u}
\end{gathered}
$$

la ecuación (A.14) queda

$$
\kappa L=\int_{0}^{\sqrt{z-u}} \frac{2 s d s}{\left(-\sum_{i} \alpha_{i}\left(e^{-v_{i}\left(\left(s^{2}+u\right)+u\right) / 2} \operatorname{senh}\left(v_{i}\left(\left(s^{2}+u\right)-u\right) / 2\right)\right)\right)^{1 / 2}}
$$


Definiendo la forma de la función $G(p, q)$ como

$$
G(p, q)=\left(-\sum_{i} \alpha_{i} e^{-v_{i}(p+q) / 2} \operatorname{senh}\left(v_{i}(p+q) / 2\right)\right)^{1 / 2}
$$

entonces es posible escribir la ecuación (A.16) en la forma compacta

$$
\kappa L=\int_{0}^{\sqrt{z-u}} \frac{2 s d s}{G\left(s^{2}+u, u\right)}
$$

La presión de disjoining, $P$, está compuesta de dos componentes, $P_{E}$ y $P_{0}$, donde cada una de estas presiones se encuentra definida por

$$
\begin{aligned}
& P_{E}=-\frac{\varepsilon \varepsilon_{0}}{2}\left(\frac{d \psi}{d x}\right)^{2} \\
& P_{0}=k T \sum_{i} n_{i}\left(\exp \left(-v_{i} y\right)-1\right)
\end{aligned}
$$

donde la presión $P_{E}$ es la fuerza electrostática y siempre es atractiva, mientras que la presión $P_{0}$ es la fuerza resultante de la presión osmótica debida a la acumulación de iones en las capas y es siempre repulsiva en el caso de placas idénticas.

Las presiones $P_{E}$ y $P_{0}$ varían con $\Psi$, pero $P_{E}+P_{0}$ es constante en cualquier punto entre las placas, que es un requerimiento para que el sistema esté en equilibrio. De esta forma, el cálculo de $P$ resulta de calcular $P_{0}$ en $x=0$, donde $d \Psi / d x=0$ y de este modo $P_{E}=0$. De este modo, usando la identidad (A.17) y la definición (A.18) es posible escribir la ecuación de $P$ en la forma

$$
P=2 n_{0} k T(G(u, 0))^{2}
$$

El cálculo de energías de interacción entre superficies planas por unidad de área depende del tipo de condiciones de borde del problema y en cualquiera de los tipos requiere el cálculo de la expresión

$$
V(L)=-\int_{\infty}^{L} P(L) d L
$$

de este modo, es posible escribir la energía de interacción para una gran variedad de situaciones físicas.

Cuando las superficies interactúan bajo regulación de carga eléctrica, el potencial eléctrico superficial $z$ debe ser encontrado usando la relación carga eléctrica superficial - potencial eléctrico superficial $\sigma(z)$ que caracteriza el proceso de regulación de carga eléctrica. Para un potencial en el plano medio, $u$, el potencial superficial, $z$, debe ser encontrado resolviendo la ecuación

$$
2 G(z, u)=\frac{e \sigma(z)}{\varepsilon \varepsilon_{0} k T \kappa}
$$

y la energía de interacción por unidad de área bajo regulación de carga eléctrica queda definida por

$$
\begin{gathered}
V_{R}(L)=\frac{n_{0} k T}{\kappa}\left(-2 \kappa L(G(u, 0))^{2}+4 \int_{0}^{u} G(y, 0) d y+4 \int_{u}^{z}(G(y, 0)-G(y, u)) d y+\right. \\
\left.2 \frac{e}{\varepsilon \varepsilon_{0} k T \kappa} \int_{z_{\infty}}^{z} \sigma(y) d y-4 \int_{z_{\infty}}^{z} G(y, 0) d y\right)
\end{gathered}
$$


Conociendo el proceso de ionización, es posible determinar la función de la carga eléctrica superficial. Por ejemplo, para el caso de superficies de vidrio y suponiendo que el mecanismo principal por el cual la superficie adquiere carga en contacto con agua es la disociación de grupos silanol,

y

$$
\begin{gathered}
\mathrm{SiOH} \leftrightarrow \mathrm{SiO}^{-}+\mathrm{H}^{+} \\
K=\frac{\left[\mathrm{SiO}^{-}\right]\left[\mathrm{H}^{+}\right]_{s}}{[\mathrm{SiOH}]}
\end{gathered}
$$

donde $K$ corresponde a la constante de disociación para los grupos superficiales y la concentración de protones, $\left[\mathrm{H}^{+}\right]_{s}$ es la actividad de los protones en la vecindad de los sitios $\mathrm{SiO}^{-}$en la superficie. La concentración de protones, $\left[\mathrm{H}^{+}\right]_{s}$ es relacionada a la actividad de los protones del bulto, $H$, por

$$
\left[H^{+}\right]_{s}=H \exp (-z)
$$

donde la concentración de protones del bulto se encuentra dada por la relación $H=10^{-p H}$ en unidades de mol/lt, y la variable $z$ corresponde al potencial eléctrico superficial adecuadamente escalado.

Como la carga superficial es debida a la disociación de grupos silanol, la densidad de carga superficial está dada por

$$
\sigma=-e\left[\mathrm{SiO}^{-}\right]
$$

La densidad superficial de grupos funcionales totales, $N_{s}$, está dada por

$$
N_{s}=\left[\mathrm{SiO}^{-}\right]+[\mathrm{SiOH}]
$$

Combinando las ecuaciones (A.25) y (A.26) es posible obtener

$$
[\mathrm{SiOH}]=\frac{\left[\mathrm{SiO}^{-}\right] \mathrm{H} \exp (-z)}{K}
$$

Luego, despejando $\left[\mathrm{SiO}^{-}\right]$de la ecuación (A.27), reemplazando la ecuación (A.29) en (A.28) y despejando para s se obtiene

$$
\sigma=-e N_{s} \frac{1}{1+(H / K) \exp (-z)}
$$

que corresponde a la expresión para la densidad de carga superficial de una superficie monoprótica.

Los parámetros a utilizar para vidrio se resumen en la tabla A.1, en esta tabla $\mathrm{p} K_{+}$y p $K_{-}$ son constantes de disociación, $N_{s}$ es número de sitios activos y $x$ es la ubicación del plano de corte. Los valores del potencial superficial a separación infinita para vidrio $\psi_{0 \text {,vidrio }}$ se obtienen del modelo ISG, los resultados obtenidos se muestran en la tabla 3 .

Tabla A.1. Parámetros utilizados en ajustes DLVO a curvas de fuerza de acercamiento experimentales y en cálculos de potencial zeta para vidrio. Constante de Hamaker efectiva de resina-vidrio de $1 \times 10^{-21} \mathrm{~J}$ (Takamura y Chow 1983$)^{12}$.

\begin{tabular}{ccccc}
\hline Material & $\mathrm{p} K_{+}$ & $\mathrm{p} K_{-}$ & $N_{s}\left(\mathrm{~m}^{-2}\right)$ & $x(\mathrm{~nm})$ \\
\hline Vidrio (sílice) & $0.6(\mathrm{a})$ & $7.2(\mathrm{a})$ & $1 \times 10^{18}(\mathrm{a})$ & $-\log (\mathrm{c})(\mathrm{a})$ \\
\hline
\end{tabular}

(a) Takamura y Wallace $(1987)^{13}$, c: concentración molar de catión.

Takamura, K.; Chow, R.S. 1983. A mechanism for initiation of bitumen displacement from oil sand. The J. Canadian Petroleum 22: 22-30

Takamura, K.; Chow, R.S. 1985. The electric properties of the bitumen/water interface. Part II. Application of the ionizable surface group model, Colloids and Surfaces, $15,35-48$. 